\title{
Tools for Change: An Examination of Transformative Learning and Its Precursor Steps in Undergraduate Students
}

\author{
Sabra Brock, ${ }^{1}$ Ionut Florescu, ${ }^{2}$ and Leizer Teran ${ }^{2}$ \\ ${ }^{1}$ Graduate School of Business, Touro College, New York, NY 10006, USA \\ ${ }^{2}$ Department of Mathematical Sciences, Stevens Institute of Technology, Hoboken, NJ 07030-5991, USA
}

Correspondence should be addressed to Sabra Brock, sabraebrock@gmail.com

Received 3 January 2012; Accepted 22 February 2012

Academic Editor: B. Marlow

Copyright (C 2012 Sabra Brock et al. This is an open access article distributed under the Creative Commons Attribution License, which permits unrestricted use, distribution, and reproduction in any medium, provided the original work is properly cited.

In this quantitative study of college students spanning three waves, the 10 theoretical precursor steps of transformational learning did predict its occurrence. The most consistent predictor was the step of reflection. Maturity and ethnicity also showed a predictive value, but college major was not a significant differentiator for transformative learning.

\section{Introduction}

Given the turbulent economic and business conditions of today [1], graduates will have to adapt to rapid change and exhibit leadership in their roles as entering professionals and managers. Transformative learning has been shown to be an effective component of leadership among teachers [2, 3], students [4-7], and religious leaders $[2,8]$, in the operating room [9] and in executive education [10]. Creating a climate designed to maximize transformative learning may help undergraduate students adjust more readily to a fast-changing workplace [11] and provide tools for future leaders facing challenges in times of change.

\section{Theoretical Background}

Transformative learning has been an important conceptual model in the development of college and adult education since Jack Mezirow proposed it more than 40 years ago as a theoretical description of the steps learners undergo in changing their worldviews. From the educator's perspective, transformative learning is when a learner is struck by a new concept or way of thinking and then follows through to make a life change; it supplements more common types of learning such as acquiring facts or learning new skills [12].

However, despite much qualitative research, little quantitative study has been made of the incidence of transformative learning or the 10 steps predicted by Mezirow to precede it
[13]. These 10 steps are (1) a disorienting dilemma, (2) a critical assessment of assumptions, (3) recognition that one's discontent and the process of transformation are shared and that others have negotiated a similar change, (4) exploration of options for new roles, relationships, and actions, (5) selfexamination with feelings of guilt or shame, (6) provisional trying of new roles, (7) planning of a course of action, (8) acquisition of knowledge and skills for implementing one's plans, (9) building of competence and self-confidence in new roles and relationships, and (10) a reintegration into one's life on the basis of conditions dictated by one's new perspective $[14,15]$.

These 10 steps may not necessarily be linear $[16,17]$, and a number of researchers have condensed the process into three or four steps [13]. One version included only the steps of critical reflection, discourse, and action [18]. Some researchers $[19,20]$ have emphasized their "disproof" of transformative learning because they have shown it not to require the first step of disorienting dilemma. Mezirow has stated that all steps are not required to experience transformative learning [14, 16] although Brock [21] showed quantitative evidence that the more of these steps remembered, the more likely transformative learning occurs.

\section{Purpose}

The purpose of this paper was to confirm to the value of the 10 precursor steps proposed by Mezirow [14] in predicting 
transformative learning, especially in the college classroom. His original research was among adults even though other transformative learning researchers have explored the usefulness of this model in studying college students $[3,12,21]$. Additional knowledge about what precedes transformative learning may indicate that curricula designed to focus on the most relevant precursor steps may increase the rate of transformative learning in the college classroom. An understanding of which students may be most open to transformative learning and its precursor steps may also help curriculum design.

Research Questions. The research questions being addressed include the following.

(1) What is the relationship of the precursor steps to the report of transformative learning among college students?

(2) Are some precursor steps better predictors of transformative learning than others? If so, what are these?

(3) Are there differences in reported transformative learning among demographic groups of college students? If so, what are these?

(4) Are there differences in transformative learning or its relationship to the precursor steps due to college major? If so, what majors appear to set more effective foundations for transformative learning?

(5) What differences in incidences of transformative learning are observed in the samples of college students collected in three successive years: 2005, 2008, and 2010 ?

\section{Method}

A series of studies measured the incidence of transformative learning and each of the 10 precursor steps as well as demographics and college majors. Samples of undergraduate populations were gathered in 2005, 2008, and 2010 from two colleges in a large metropolitan area in the Northeast United States via a web survey. Total sample sizes for each year are 298,454 , and 468, respectively. The 2005 sample consisted of traditional age undergraduates (mean age 19), whereas the later two samples had mean ages of 26 and 27.

4.1. Instrument. Data describing students' experiences were collected using a quantitative survey, previously validated through use of an expert panel and multiple pretests [22]. It covered the 10 steps leading to transformative learning and the reporting of transformative learning, as well as questions on demographics and college major. Recall of each of these precursor steps was measured by check boxes and included the option to say "none," followed by a question whether or not transformative learning occurred while at this institution. Those respondents reporting transformative learning were asked to explain in their own words how they experienced it. These open-ended responses were used to confirm that students reporting transformative learning understood that it was not merely learning a new tool, such as SWOT. For this study, the instrument was modified to add class rank in the demographic section. This paper-based survey was first piloted to assure the original method would be replicable on the web.

4.2. Procedures. Participation in all three studies was voluntary and had been approved by the colleges' Institutional Review Boards. In 2005, the Dean of the Undergraduate School helped recruit students. Recruitment invitations were included in four editions of the school's weekly e-newsletter. Those students interested in volunteering were directed to a link for a website (surveymonkey.com) displaying the survey. In the 2008 and 2010 studies, undergraduate students were emailed directly and offered a link to the surveymonkey.com website. In the 2005 study, participants were offered participation in a $\$ 250$ lottery as suggested by Dillman [23] to increase response rate. No incentive was offered in the latter two studies, but in all three the offer was made to provide a summary of the completed results if an email address was provided. Response rate was $13 \%$ in the 2005 study, with the relatively low level being attributed to the invitation appearing at the end of the Dean's letter and "below the fold" of this electronic communication [24]. In the latter two studies, the response rate to the more direct solicitation was $60 \%$ (2008) and 61\% (2010). Split half reliability was checked between responders and nonresponders in each of the three samples.

\section{Findings}

5.1. Research Question 1: What Is the Relationship of the Precursor Steps to the Report of Transformative Learning among College Students? Recalling the precursor steps predicted transformative learning in logistic regression modeling. The model used the following formula, where $P$ is the percent answering "yes" answer to recalling an experience of transformative learning and $\beta_{1}-\beta_{13}$ are measures of the individual precursor steps and epsilon a Gaussian error term

$$
\log \left(\frac{p}{1-p}\right)=\beta_{0}+\beta_{1} X_{1}+\cdots+\beta_{k} X_{k}+\varepsilon .
$$

For the 2005, 2008, and 2010 samples, the respective Cragg Uhler Nagelkerke pseudo $R^{2}$ measures were 0.316 , 0.231 , and 0.357 and the McFadden pseudo $R^{2}$ measures were $0.196,0.138$, and 0.229 , indicating a good fit in 2010 and a borderline good fit in 2005. Furthermore, using the model to predict from one sample to another showed large numbers for a logistic model. See Table 1.

Checking any of the precursor steps predicted transformative learning. Further, indicating having experienced none of the precursor steps predicted a "no" to experiencing transformative learning and improved the fit of the model. See Table 2.

Also the more of the precursor steps remembered, the higher the likelihood that students reported experiencing transformative learning. The $\beta$ coefficients for the addition of the precursor steps to the logistic regression model were 
TABLE 1: Transformative learning prediction power of models using precursor steps.

\begin{tabular}{lccc}
\hline & $\begin{array}{c}2005 \text { Wave } \\
\text { predicted transformative } \\
\text { learning }\end{array}$ & $\begin{array}{c}2008 \text { Wave } \\
\text { predicted transformative } \\
\text { learning }\end{array}$ & $\begin{array}{c}2010 \text { Wave } \\
\text { predicted transformative } \\
\text { learning }\end{array}$ \\
\hline Model using 2005 precursor step data & $70.1 \%$ & $62.3 \%$ & $69.4 \%$ \\
Model using 2008 precursor step data & $64.1 \%$ & $67.6 \%$ & $72.9 \%$ \\
Model using 2010 precursor step data & $66.8 \%$ & $66.1 \%$ & $73.5 \%$ \\
\hline
\end{tabular}

TABLE 2: Transformative learning prediction power adding "no" check to precursor steps.

\begin{tabular}{lccc}
\hline & 2005 Wave & 2008 Wave & 2010 Wave \\
\hline $\begin{array}{l}\text { Base = checked at least one precursor step and also reported } \\
\text { transformative learning }\end{array}$ & $61.4 \%$ & $64.0 \%$ & $62.5 \%$ \\
$\begin{array}{l}\text { Base = checked "none of the precursor steps remembered" and did not } \\
\text { report transformative learning }\end{array}$ & $79.5 \%$ & $70.4 \%$ & $80.7 \%$ \\
$\begin{array}{l}\text { Combination of when precursor steps predicted either reporting } \\
\text { transformative learning or not }\end{array}$ & $64.1 \%$ & $67.2 \%$ & $72.6 \%$ \\
\hline
\end{tabular}

$0.33,0.19$, and 0.28 in 2005,2008 , and 2010, respectively. Saying "none of the precursor steps remembered" was a strong predictor of transformative learning in the 2008 and 2010 waves with negative $\beta$ coefficients of -0.93 and -1.12 . In other words, remembering none of the steps appeared to mean that transformative learning did not happen.

5.2. Research Question 2. Are Some Precursor Steps Better Predictors of Transformative Learning Than Others? If So, What Are These? In order to address the relationship between specific precursor steps and transformative learning, likelihood ratio tests [25] were conducted between each of the 10 precursor steps and reported transformative learning. Associations were observed, but only one of the steps predicted transformative learning in all three samples: the step of reflection. Respondents could frame this step in one of two ways: reflecting by critically looking at existing assumptions or noncritically in staying with existing assumptions. In 2005 and 2010, critical reflection resulting in changed assumptions significantly predicted transformative learning; in 2005, this precursor step was much more important than other steps. In the 2008 and 2010, waves reflection that occurred without changing assumptions also significantly predicted not reporting transformative learning.

The precursor stop of a disorienting dilemma was predictive in the first two waves. Trying on new roles and acquiring skills/knowledge to implement plan significantly predicted transformative learning in the 2005 and 2010 waves. Building confidence was a significant predictor in the 2010 sample. The following steps showed no significant relationship to transformative learning in any of the waves: recognizing discontent shared, exploring new roles (as contrasted to trying new roles), self-examination with feelings of guilt/shame, planning a new course of action, and reintegrating to life.

5.3. Research Question 3: Are There Differences in Reported Transformative Learning among Demographic Groups? If So, What Are These? Six demographic variables were examined for relationship to the recollection of transformative learning: class standing, semesters completed, age, prior education, gender, and ethnicity. The only demographic variables to have a significant relationship to transformative learning in all three waves of this paper were age and ethnicity.

In the 2005 study, significant relationships to reported transformative learning were found in age with the more mature student reporting higher rates of transformative learning. Older students did report greater rates of transformative learning in the 2010 sample as did students who had qualified for college with the nontraditional GED (graduate equivalent diploma). Gender, class standing, and semesters completed did not have significant relationships with reported transformative learning in any of the three studies. Ethnicity had a significant relationship with transformative learning at the .05 level in 2008 and 2010 with Hispanics reporting it at a higher rate. Note that each of the three prior demographic measures was determined by checkboxes.

\subsection{Research Question 4. Are There Differences in Transforma-} tive Learning or Its Relationship to the Precursor Steps due to College Major? If So, What Majors Appear to Set More Effective Foundations for Transformative Learning? There were no significant differences in transformative learning or the 10 precursor steps and college major in any of the three samples.

5.5. Research Question 5. What Differences in Incidences of Transformative Learning Are Observed between the Samples Collected in Three Successive Years: 2005, 2008, and 2010? The incidence of reporting transformative learning was 55.4\% in the 2005 sample, $46.9 \%$ in the 2008, sample and 38.5\% in the 2010 sample, indicating significant differences. These incidences fall within the range reported in the transformative learning literature $[26,27]$.

There are differences in the respondent bases with the 2005 sample being full-time business school undergraduates and the 2008 and 2010 samples being a combination of full and part time undergraduate of all majors at another 
college. King's 1997 sample was students enrolled in evening programs and her 2000 study was among ESL students.

\section{Discussion and Recommendations}

In summary, incidences of transformative learning varied across time and samples, confirming the range found in the limited reporting of quantitative studies of transformative learning $[21,26,27]$. The precursor steps to transformative learning proposed by Mezirow [14] relate to the reporting of transformative learning. Checking any of them predicted transformative learning and checking none predicted not reporting transformative learning. The precursor step of reflection, as Mezirow has argued [16, 28], may be the most important of the precursor steps although reflecting without a consciousness of changing assumptions appears not to create a fertile climate for transformative learning.

These findings provide a foundation for assessing whether transformative learning has occurred in the classroom and the range that can be considered normative. It does support discussions in the educational literature that transformative learning is related to the maturation process. This finding is important in that educators are encouraged not just to celebrate the sudden "a-ha" type of learning but continue to stimulate the more gradual change of framework that occurs over time. The work of Perry and other stage theorists may be useful in framing how incremental transformative learning can be fostered [29-31]. In looking back over a semester, learners can be surprised that life lessons have been learned. Reflecting on behavior and life can foster seeing the world in a new way.

The study results seem to indicate that educational techniques that especially encourage five of the 10 transformative learning precursor steps may be most effective in fostering this type of learning. These are reflecting critically on assumptions, as well as experiencing disorienting dilemmas, trying on new roles, acquiring skills to make a change, and building confidence. Mezirow has strongly defended the inclusion of critical reflection as one of these steps [32] in reaction to suggestions to change his original definition [20].

Implications for practice point to more inclusion of reflective exercises such as learning journals, especially after incorporating new and challenging ideas into the classroom. The transformative learning process is enhanced as students can then be supported through the trying out of new roles these ideas imply, practicing skills necessary to implement them, and gaining confidence in their new world view.

\section{Limitations and Future Research}

This study was limited to two undergraduate colleges at three points in time in a major Northeastern city in the United States. Therefore, the results may be only generalized to similar contexts. Future research is recommended to extend this research to other schools and other populations of learners. The differences in life style among the three waves of this paper may help to explain why the incidence of transformative learning varied. The highest rate was in the school where students were enrolled full-time (2005). Some of the students in the other two samples had full-time jobs and family responsibilities outside school, probably creating different dynamics for transformative learning.

Although some research exists showing a connection between transformative learning and being prepared to manage change [3,9-11], more research, especially longitudinal research, is needed to strengthen this connection in times of change.

\section{References}

[1] S. Eisner, "E-employment? College grad career building in changing and electronic age," American Journal of Business Education, vol. 3, no. 7, pp. 25-40, 2010.

[2] G. Forrester, G. Motteram, and L. Bangxiang, "Transforming Chinese teachers' thinking, learning and understanding via elearning," Journal of Education for Teaching, vol. 32, no. 2, pp. 197-212, 2006.

[3] S. Harris, H. Lowery-Moore, and V. Farrow, "Extending transfer of learning theory to transformative learning theory: a model for promoting teacher leadership," Theory Into Practice, vol. 47, no. 4, pp. 318-326, 2008.

[4] D. J. Glisczinski, "Transformative higher education: a meaningful degree of understanding," Journal of Transformative Education, vol. 5, no. 4, pp. 317-328, 2007.

[5] L. Hanson, "Global citizenship, global health, and the internationalization of curriculum: a study of transformative potential," Journal of Studies in International Education, vol. 14, no. 1, pp. 70-88, 2010.

[6] R. Kelly and B. Fetherston, "Conflict resolution and transformative pedagogy: a grounded theory research project on learning in higher education," Journal of Transformative Education, vol. 5, no. 3, pp. 262-285, 2007.

[7] K. M. Brown, "Leadership for social justice and equity: evaluating a transformative framework and andragogy," Educational Administration Quarterly, vol. 42, no. 5, pp. 700-745, 2006.

[8] R. C. Clare, "Putting faith into action: a model for the north American middle class," Religious Education, vol. 101, no. 3, pp. 368-389, 2006.

[9] M. E. McNaron, "Using Transformational Learning Principles to Change Behavior in the OR," AORN Journal, vol. 89 , no. 5 , pp. 851-860, 2009.

[10] R. Ciporen, The Role of Personally Transformative Learning in Leadership Development: A Case Study Examining the Transfer of Learning from an Executive Education Program, Columbia University, 2009.

[11] S. Wills, "2001: a research odyssey-teaching different types of learning," The Journal of Management Development, vol. 13, no. 1, pp. 60-74, 1994.

[12] P. Cranton, Understanding and Promoting Transformative Learning, Jossey-Bass, San Francisco, Calif, USA, 2006.

[13] E. W. Taylor, "An update of transformative learning theory: a critical review of the empirical research (1999-2005)," International Journal of Lifelong Education, vol. 26, no. 2, pp. 173191, 2007.

[14] J. Mezirow, Education for Perspective Transformation: Women Re-Entry Programs for Community College, Center for Adult Education, Teachers College, Columbia University, New York, NY, USA, 1978. 
[15] J. Mezirow, "Learning to think like an adult," in Learning as Transformation: Critical Perspectives on a Theory in Progress, J. M. Associates, San Francisco, Calif, USA, 2000.

[16] J. Mezirow, "Understanding transformation theory," Adult Education Theory, vol. 46, pp. 22-32, 1994.

[17] P. Cranton, Understanding and Promoting Transformative Learning: A Guide for Educators of Adults, Jossey-Bass, San Francisco, Calif, USA, 1994.

[18] S. Merrimam and R. Caffarella, Learning in Adulthood, JosseyBass, San Francisco, Calif, USA, 1999.

[19] D. Kilgore and L. Bloom, "When I'm down, it takes me a while: rethinking transformational education through narratives of women in crisis," Adult Basic Education, vol. 12, no. 3, pp. 123$133,2002$.

[20] J. T. Kovan and J. M. Dirkx, "Being called awake: the role of transformative learning in the lives of environmental activists," Adult Education Quarterly, vol. 53, no. 2, pp. 99-118, 2003.

[21] S. E. Brock, "Measuring the importance of precursor steps to transformative learning," Adult Education Quarterly, vol. 60, no. 2, pp. 122-142, 2010.

[22] K. King, A Guide to Perspective Transformation and Learning Activities: The Learning Activities Survey, Research for Better Schools, Philadelphia, Pa, USA, 1998.

[23] D. Dillman, Mail and Internet Surveys, John Wiley \& Sons., New York, NY, USA, 2000.

[24] P. Lynch and S. Horton, Web Style Guide, Yale University Press, New Haven, Conn, USA, 2001.

[25] G. Casella and R. Berger, Statistical Inference, Duxbury Resource Center, Pacific Grove, Calif, USA, 2001.

[26] K. King, "Examining activities that promote perspective transformation among adult learners in adult education," International Journal of University Adult Education, vol. 36, no. 3, pp. 23-37, 1997.

[27] K. P. King, “The adult ESL experiences: facilitating perspective transformation in the classroom," Adult Basic Education, vol. 10, no. 1, pp. 69-89, 2000.

[28] J. Mezirow, "On critical reflection," Adult Education Quarterly, vol. 48, no. 3, pp. 185-193, 1998.

[29] M. Baxter Magolda, Ed., Teaching to Promote Intellectual and Personal Maturity: Incorporating Students' World Views and Identities Into the Learning Process, Jossey-Bass, San Francisco, Calif, USA, 2000.

[30] R. Kegan, In Over Our Heads, Harvard University Press, Cambridge, Mass, USA, 1994.

[31] W. Perry, Forms of Intellectual and Ethical Development in the College Years, Holt, Rinehart and Winston, New York, NY, USA, 1970.

[32] J. Mezirow, “Transformative learning as discourse," Journal of Transformative Education, vol. 1, no. 1, pp. 58-63, 2003. 

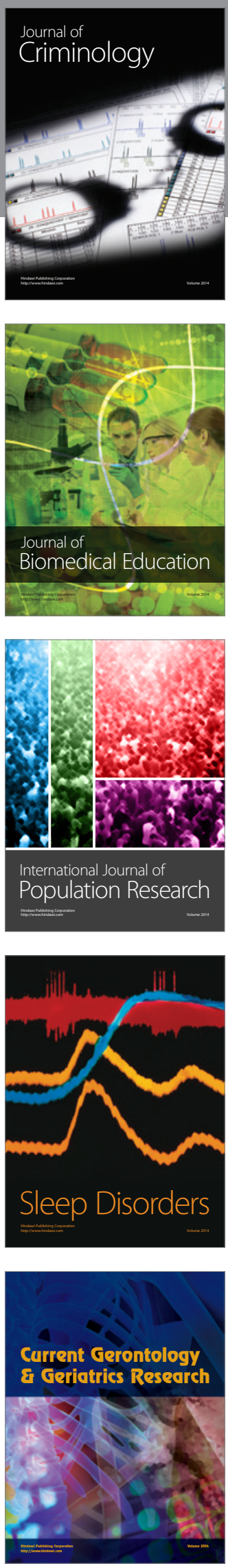
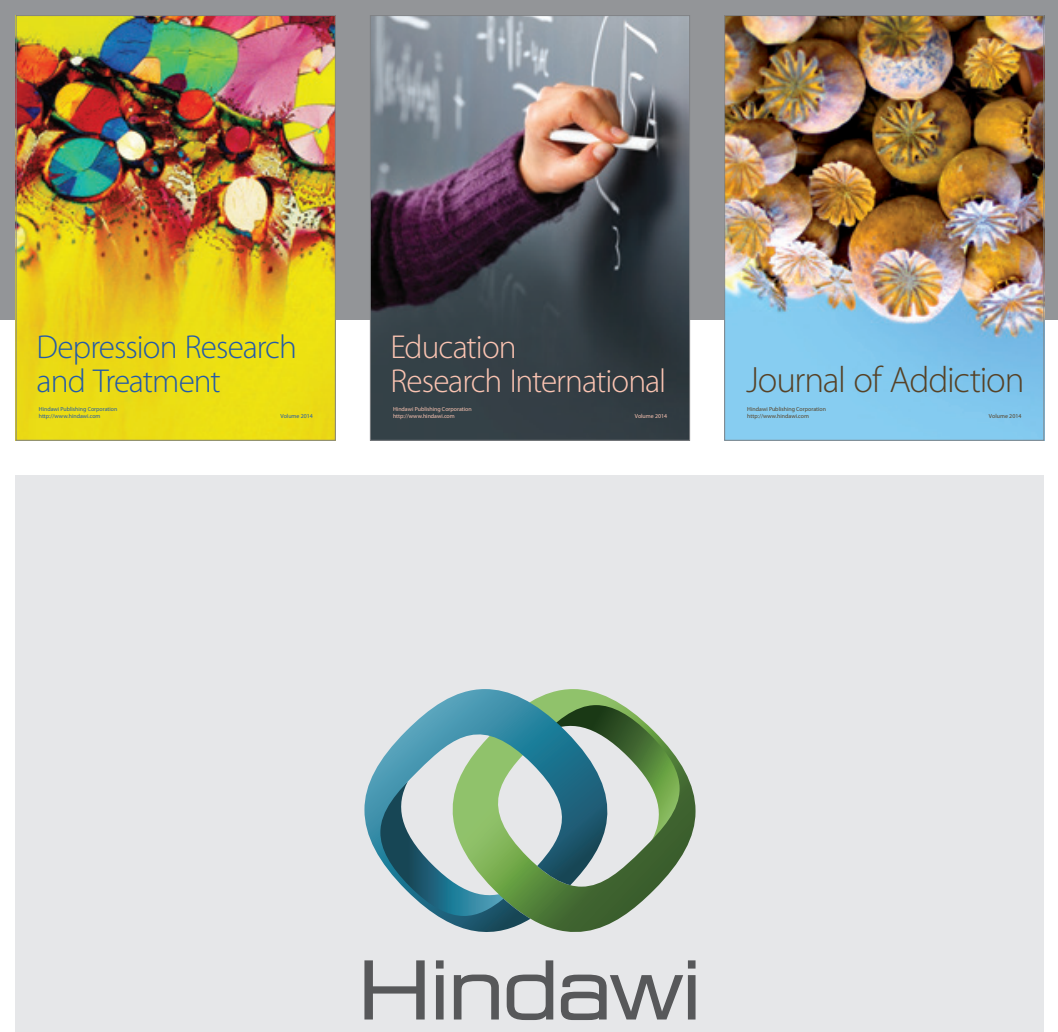

Submit your manuscripts at

http://www.hindawi.com

Child Development Research
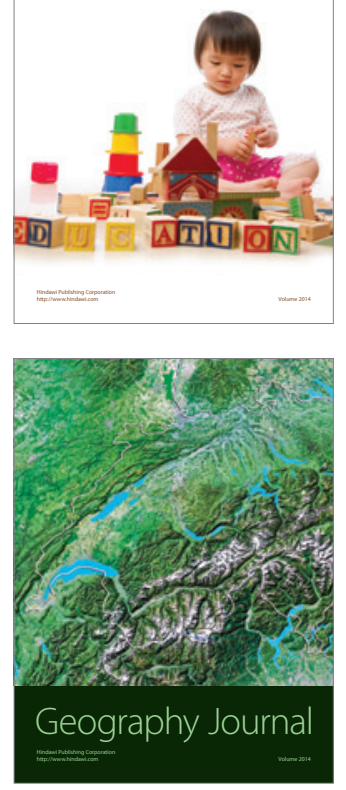

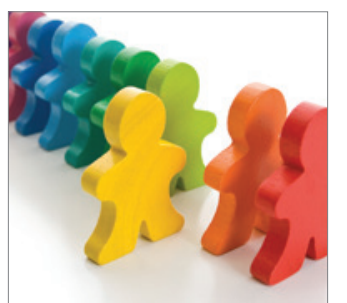

Autism

Research and Treatment
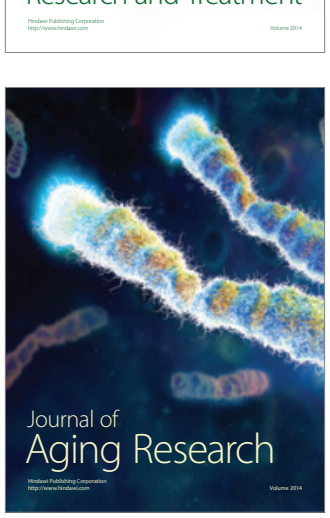
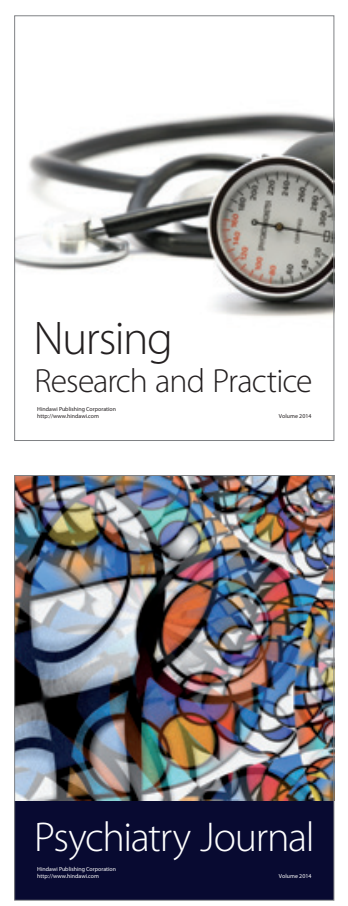
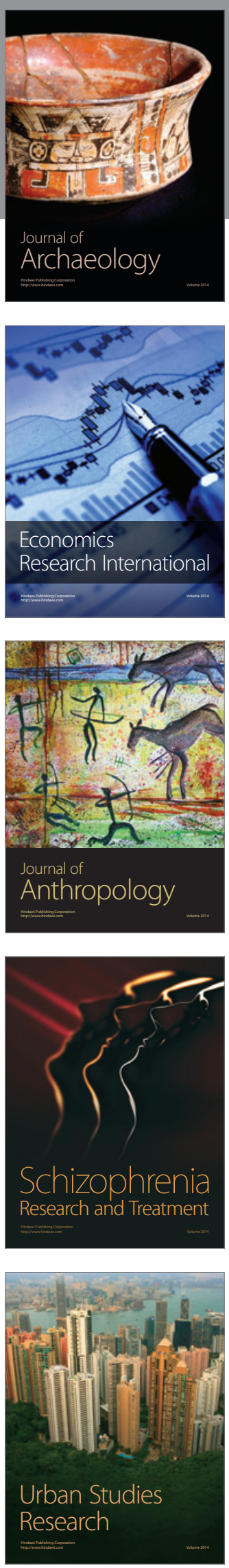